University of Nebraska - Lincoln

DigitalCommons@University of Nebraska - Lincoln

\title{
$5-2009$
}

\section{Effects of the polycyclic musk HHCB on individual- and population-level endpoints in Potamopyrgus antipodarum}

\author{
Signe Pedersen \\ Roskilde University, sipe@ruc.dk \\ Henriette Selck \\ Roskilde University, hse@virgil.ruc.dk \\ Daniel Salvito \\ Roskilde University, dsalvito@rifm.org \\ Valery E. Forbes \\ University of Nebraska-Lincoln, veforbes@umn.edu
}

Follow this and additional works at: https://digitalcommons.unl.edu/biosciforbes

Part of the Environmental Health Commons, Terrestrial and Aquatic Ecology Commons, and the Toxicology Commons

Pedersen, Signe; Selck, Henriette; Salvito, Daniel; and Forbes, Valery E., "Effects of the polycyclic musk HHCB on individual- and population-level endpoints in Potamopyrgus antipodarum" (2009). Valery Forbes Publications. 49.

https://digitalcommons.unl.edu/biosciforbes/49

This Article is brought to you for free and open access by the Papers in the Biological Sciences at DigitalCommons@University of Nebraska - Lincoln. It has been accepted for inclusion in Valery Forbes Publications by an authorized administrator of DigitalCommons@University of Nebraska - Lincoln. 


\title{
Effects of the polycyclic musk HHCB on individual- and population-level endpoints in Potamopyrgus antipodarum
}

\author{
Signe Pedersen, ${ }^{1}$ Henriette Selck, ${ }^{1}$ Daniel Salvito, ${ }^{2}$ and Valery Forbes ${ }^{1}$ \\ 1. Center for Integrated Population Ecology, Department of Environmental, Social and Spatial Change, \\ Roskilde University, Universitetsvej 1, P.O. Box 260, DK-4000 Roskilde, Denmark \\ 2. Research Institute for Fragrance Materials, 50 Tice Boulevard, Woodcliff Lake, NJ 07677, USA
}

\begin{abstract}
Although the polycyclic musk 1,3,4,6,7,8-hexahydro-4,6,6,7,8,8-hexamethylcyclopenta[ץ]-2-benzopyran (HHCB) is frequently detected in aquatic sediments, very little is known about its effects on sediment-feeding organisms. Effects of sediment-associated HHCB on growth, feeding rate, survival and reproduction in the gastropod Potamopyrgus antipodarum were measured in the laboratory. Snails were exposed to six nominal $\mathrm{HHCB}$ concentrations: 0, 0.1,1,10, 30 and $100 \mu \mathrm{g} \mathrm{g} \mathrm{g}^{-1}$ dry weight (dw) sediment. Adult survival and growth were not affected by HHCB. However, juvenile growth and survival, reproduction, time to first reproduction and adult feeding rate were more sensitive endpoints and declined with increasing HHCB concentration. Individual-level endpoints for $P$. antipodarum were integrated into a population model to investigate the effects of HHCB on population growth rate. Under otherwise favorable laboratory conditions, population growth rate was slightly (by ca. 2\%), but not significantly, reduced with increasing HHCB exposure concentration. Model simulations were performed to explore the consequences of HHCB exposure under more ecologically realistic conditions (i.e., survival and reproduction of unexposed snails were markedly reduced relative to the laboratory). The results suggest that despite detectable effects of HHCB on individual-level endpoints measured in the laboratory, impacts on population dynamics of this deposit feeder are not likely to occur at environmentally relevant exposure concentrations.
\end{abstract}

Keywords: Deposit feeder, Life-table response experiment, Elasticity, Fragrance materials, Population growth rate, Sediment

\section{Introduction}

Although toxicant effects are most frequently measured in terms of individual performance, it is the impacts on populations and the communities and ecosystems of which they are a part that are of primary concern for risk assessment (Forbes et al., 2006). One of the main difficulties in assessing the ecological risks of toxic substances is in linking effects on individual-level endpoints measured in toxicity tests to ecologically relevant impacts (Levin et al., 1996; Forbes and Calow, 2002). It has been shown that there is not necessarily a simple link between effects measured at the individual level and effects occurring at the population level (Kammenga et al., 1996; Forbes and Calow, 1999). A large number of studies have demonstrated the value of using demographic models to link individual- to population-level effects of chemicals and other stressors (Hansen et al., 1999a, 1999b; Linke-Gamenick et al., 1999; Caswell, 2001; Widarto et al., 2004; Barnthouse et al., 2008; Akçakaya et al., 2008).

The present study was designed to quantify effects of the polycyclic musk fragrance 1,3,4,6,7,8-hexahydro-4,6,6,7,8,8hexamethylcyclopenta[ $\gamma]$-2-benzopyran $(\mathrm{HHCB})$ on the deposit- feeding gastropod, Potamopyrgus antipodarum. More specifically, chronic effects of sediment-bound HHCB were measured on different individual life-history traits (juvenile and adult survival, time to first reproduction, size at first reproduction and reproductive output), as well as on individual growth and feeding rate. Subsequently, the measured effects on the individual life-history traits were integrated into a population model to assess the likely risks of $\mathrm{HHCB}$ for $P$. antipodarum population dynamics.

HHCB is a polycyclic musk fragrance that is used in various products, including cosmetics, detergents, shampoos, soap, washing powder and household-cleaning products (Balk and Ford, 1999a, 1999b; Balk et al., 2004; Reiner and Kannan, 2006). HHCB is one of the most widely used polycyclic musks (Rimkus, 1999), representing (together with 6-acetyl-1,1,2,4,4,7-hexamethyltetraline (AHTN)) about $95 \%$ of the total market volume of this group of chemicals (Balk and Ford, 1999b; Rimkus, 1999). Though the use of HHCB in Europe appears to be slightly declining, it is still substantial and was 2400 tons in 1992 (Plassche and Balk, 1997), 1481 tons in 1995, 1473 tons in 1998 (Balk et al., 2004) and 1427 tons in 2000 (HERA, 2004). After use most of the HHCB is released down 
the drain to wastewater treatment plants. Consequently, HHCB has been detected in sewage sludge, influent and effluent (Simonich $e t$ al., 2002; Berset et al., 2004; DiFrancesco et al., 2004; Kupper et al., 2004; Bester, 2005; Horii et al., 2007; Reiner et al., 2007). The release to wastewater treatment plants is HHCB's primary route into the environment, since it is not completely removed during the treatment process. The continuous production and use of $\mathrm{HHCB}$ result in a constant input into wastewater treatment plants and thereby a steady input into the aquatic environment.

The first reported occurrence of polycyclic musks, including $\mathrm{HHCB}$, in different environmental compartments was published by Esche et al. (1994). Subsequently, HHCB has been reported in lake and river water (Peck and Hornbuckle, 2004; Moldovan, 2006), in the North Sea (Bester et al., 1998), in biota such as mussels and fish (Fromme et al., 2001a; Gatermann et al., 2002) as well as in top predators, e.g. porpoises, sharks, otters, seals and dolphins (Kannan et al., 2005; Nakata et al., 2007).

HHCB has been found in suspended particulate matter and in sediment at a concentration range $0.002-2.2 \mu \mathrm{g}$ HHCB g ${ }^{-1}$ dry weight (dw) sediment (Lach and Steffen, 1997; Fromme et al., 2001b; Dsikowitzky et al., 2002).

In the present study we exposed a deposit-feeding gastropod to sediment-associated HHCB. Given its route of entry into the environment and its hydrophobic properties ( $\log K_{\mathrm{ow}}=5.9$ ), sediment is likely to be an important environmental compartment for HHCB. Since deposit feeders use sediment as their food source and ingest one to many times their own body weight in sediment daily (Lopez and Levinton, 1987), these animals are particularly susceptible to exposure to sediment-bound toxicants. Because deposit feeders represent an important link in aquatic food chains and play a key role in the recycling of organic matter, impacts on the populations of such organisms are of concern (EC, 2003).

\section{Methods}

\subsection{Study organism}

P. antipodarum is a deposit-feeding gastropod that inhabits the upper layers of freshwater and brackish sediments. P. antipodarum was introduced from New Zealand to Europe in the late 1800s and has since spread throughout most of Europe (Ponder, 1988; Jacobsen et al., 1996). More recently the species has been found in the western United States (Hall et al., 2006).

In Europe $P$. antipodarum reproduces by parthenogenesis, and populations generally consist of a single genetic clone (Jacobsen et al., 1996). Snails start to reproduce when they reach a shell length of 3.1-4.0 mm (Dahl and Winter, 1993; Jensen et al., 2001), and adults may reach a shell length of up to $6 \mathrm{~mm}$. $P$. antipodarum is ovoviviparous, and the duration of the embryonic stage is 30-35 days at $15{ }^{\circ} \mathrm{C}$ (Dorgelo, 1991). P. antipodarum and several closely related species of the genus Hydrobia are important representatives of temperate surface-deposit-feeding species.

P. antipodarum were collected at Salvad Park, Roskilde Fjord, Denmark, in 2004 and subsequently reared in $10 \mathrm{~L}$ aquaria at $17{ }^{\circ} \mathrm{C}$ on natural pre-frozen sediment $(<250 \mu \mathrm{m})$ and artificial freshwater $\left(192 \mathrm{mg} / \mathrm{L} \mathrm{NaHCO}_{3}, 8 \mathrm{mg} / \mathrm{L}\right.$ $\mathrm{KCl}, 245 \mathrm{mg} / \mathrm{L} \mathrm{MgSO}_{4}$ and $120 \mathrm{mg} / \mathrm{L} \mathrm{CaSO}_{4}$ in de-ionized water, $\mathrm{pH} 7.2$ (Jensen et al., 2001)). A food supplement of commercial fish food (Tetra Min, Tetra Werke, Melle, Germany), baby cereal (Milpo, Milupa, Hørsholm, Denmark) and dried spinach in equal ratios by weight was added to cultures twice a week. The overlying water was renewed every month, and every 4-6 weeks the cultures were given 3-4 spoonfuls of fresh pre-frozen sediment.

\subsection{Preparation of sediment}

All sediments used in the experiments were collected from a shallow area in Roskilde Fjord away from potential point sources of pollutants (Store Havelse, Roskilde fjord, Denmark). The top $5 \mathrm{~cm}$ of the surface sediment were collected and sieved $(<63 \mu \mathrm{m})$ using de-ionized water and then frozen until use $\left(-20{ }^{\circ} \mathrm{C}\right)$. The sieved sediment had a water content of $71.6 \pm 0.15 \%$ $\left(24 \mathrm{~h}\right.$ at $\left.105{ }^{\circ} \mathrm{C} ; n=3\right)$, an organic content of $11.7 \pm 0.13 \%\left(6 \mathrm{~h}\right.$ at $550{ }^{\circ} \mathrm{C}$; $n=3$ ) and a carbon content of $5 \% \pm 0.2 \%$ (EA 1110 CHNS-elemental analyzer; $n=3$ ). The nominal concentrations of $\mathrm{HHCB}$ were 0 ( = control), $0.1,1$, 10,30 and $100 \mu \mathrm{g} \mathrm{HHCB} \mathrm{g}{ }^{-1} \mathrm{dw}$ sediment to cover the range from environmentally realistic concentrations to those approaching toxic effect concentrations for growth of P. antipodarum determined in a 2-week pilot experiment.
Unless otherwise indicated, concentrations of $\mathrm{HHCB}$ are presented as nominal concentrations.

An HHCB-contaminated stock sediment $\left(500 \mu \mathrm{g}\right.$ HHCB g ${ }^{-1}$ dw sediment was made by adding a known amount of fluid HHCB to a glass container followed by a known volume of wet sediment. Subsequently, the glass container was shaken for $24 \mathrm{~h}$ in the dark. The five HHCB treatments were made by adding a known amount of wet stock sediment to a known volume of non-spiked wet sediment in a glass container. The glass containers were left on a shaking table for $24 \mathrm{~h}$ in the dark. Nominal HHCB concentrations were estimated by accounting for water content of the sediment. The sediment was homogenized before being divided into smaller portions and subsequently frozen until use $\left(-20^{\circ} \mathrm{C}\right)$.

\subsection{Extraction and analysis of $\mathrm{HHCB}$}

Sediments were extracted using an accelerated solvent extraction system, ASE200 (Dionex, Hvidovre, Denmark) based on the method used by Difrancesco et al. (2004) and Simonich et al (2000) with some modifications. The sediment samples were homogenized using a hand-held mixer. The water content was determined by drying the sediment at $105^{\circ} \mathrm{C}$ for $15 \mathrm{~h}$. Approximately $2 \mathrm{~g}$ sediment was spiked with acetyl cedrene (as an internal standard) and thoroughly mixed with $2 \mathrm{~g}$ Hydromatrix (Varian, Palo Alto, CA, USA) to create a free-flowing mixture. Hydromatrix absorbs water from the sediment, creates a larger surface area, reduces clumping and facilitates even dispersal of the solvent in the sediment. For each sample, a $33 \mathrm{ml}$ extraction cell was used, which was packed with $3 \mathrm{~g}$ silica gel (activated for $15 \mathrm{~h}$ at $105^{\circ} \mathrm{C}$ ) as a clean up step. The sediment-Hydromatrix mixture was added to the cell, and the cell was filled with Hydromatrix approximately $1 \mathrm{~cm}$ from the top and packed tightly. Triplicates were made for all concentrations.

The cells were extracted with $30 \mathrm{ml}$ dichloromethane (DCM) at $60{ }^{\circ} \mathrm{C}$ and $2000 \mathrm{psi}(138 \mathrm{bar})$ in static mode for $15 \mathrm{~min}$. The extraction took approximately 45 min per sample.

Sodium sulfate was added to the extracts from the three highest concentrations $\left(10,30\right.$ and $\left.100 \mu \mathrm{g} \mathrm{HHCB} \mathrm{g}{ }^{-1}\right)$ to bind water. The sodium sulfate was allowed to settle, and the extracts were transferred to GC-MS vials.

One milliliter toluene was added to the extracts from $0,0.1$ and $1 \mu \mathrm{g} \mathrm{HHCB} \mathrm{g}{ }^{-1} \mathrm{dw}$ sed, which were evaporated to a total volume of $1 \mathrm{ml}$ (SE 500, Dionex, Hvidovre, Denmark) and transferred to GC-MS vials.

All extracts were analyzed by GC-MS using an Agilent 6890 GC-5973 MS equipped with a J\&W DB-1701 capillary column $(30 \mathrm{~m}, 0.25 \mathrm{~mm}$ i.d., $0.25 \mu \mathrm{m}$ film thickness) and an Agilent 7683 autosampler. Samples were analyzed using selective ion monitoring, and each compound was identified and quantified based on a quantification ion (243) and two confirmation ions (213 and 258). The ionization mode was electron impact $(70 \mathrm{eV})$, the ion source temperature was $230^{\circ} \mathrm{C}$ and the dwell time was $25 \mathrm{~ms} / \mathrm{ion}$. The GC temperature program was isothermal at $35{ }^{\circ} \mathrm{C}$ for $2 \mathrm{~min}, 5{ }^{\circ} \mathrm{C} / \mathrm{min}$ to $200{ }^{\circ} \mathrm{C}$ and $20{ }^{\circ} \mathrm{C} / \mathrm{min}$ to $280{ }^{\circ} \mathrm{C}$ for $2 \mathrm{~min}$. All samples were analyzed on the GC-MS using a split/splitless injector in splitless mode.

\subsection{Experimental design}

To investigate the effects of $\mathrm{HHCB}$ on selected life-history traits and feeding rate, snails were exposed individually with 10 replicates per treatment. The snails were exposed in $5 \mathrm{ml}$ Nunclon multi-well dishes (NUNC A/S, Roskilde, Denmark) containing $0.5 \mathrm{ml}$ wet sediment $(\approx 0.3 \mathrm{~g} \mathrm{dw}$ sediment) and $2.5 \mathrm{ml}$ oxygenated artificial freshwater. Wells were monitored once a week, and snails were transferred to new wells containing fresh experimental sediment. The wells were prepared 1 day before they were used for the experiment and left in the dark overnight. The overlying water was renewed with clean oxygenated water $1 \mathrm{~h}$ prior to transferring the snails to the wells. The lids on the wells were covered with wet paper towels and aluminum foil to minimize water evaporation during the experiments. The experiments were conducted in the dark at $17^{\circ} \mathrm{C}$ and $2 \mathrm{ml}$ of the overlying water was renewed every second day to avoid oxygen deficiency.

Due to the long lifespan of $P$ antipodarum (16-17 months) the experiment was divided into two parallel experiments: (i) juveniles exposed from birth to first reproduction to measure juvenile survival, growth, time to first reproduction and size at first reproduction and (ii) adults exposed for 12 weeks to measure growth rate and reproduction. An additional 6-week experiment was carried out with adult snails to measure $\mathrm{HHCB}$ effects on feeding rate.

\subsubsection{Juvenile growth, survival, time to first reproduction and size at first reproduction}

Sixty adult snails were transferred to a $1-\mathrm{L}$ aquarium with $0.5 \mathrm{~cm}$ sediment and allowed to reproduce for 1 week, where after they were removed from the aquarium. After 8 weeks, juveniles were collected with a pipette from the aquarium, randomly placed individually in dishes with clean artificial fresh- 
water and videotaped to measure shell length. Subsequently, the snails were transferred individually to wells containing experimental sediment as described above.

A video camera mounted on a dissection microscope was used to record snails, and individual shell length $(L)$ was measured using an image analysis program (SigmaScan ${ }^{\oplus}$ Pro. version 5.0, Jandel, Erkrath, Germany). Juvenile snail shell lengths were measured every 3 weeks over a 12 -week period. Specific growth rates (SGRs) from week 0 to week 12 were estimated following Kaufmann (1981):

$\mathrm{SGR}=\frac{\ln S_{2}-\ln S_{1}}{t_{2}-t_{1}}$

where $S_{1}$ and $S_{2}$ are the shell lengths at time $t_{1}$ (week 0 ) and $t_{2}$ (week 12), respectively.

Survival was recorded each week when the snails were transferred to new wells. After 30 weeks, which is close to the minimum age at first reproduction under these conditions (Jensen et al., 2001), the wells were examined for offspring every week until almost all snails had reproduced by week 43 . There were two individuals that did not reproduce (one at $30 \mu \mathrm{g} \mathrm{HHCB} \mathrm{g}{ }^{-1}$ and one a $100 \mu \mathrm{g} \mathrm{HHCB} \mathrm{g}{ }^{-1}$ ), and these were not included in the analysis of time to first reproduction. At the time to first reproduction, shell lengths of the reproducing snails were measured as described above.

\subsubsection{Adult growth, survival and reproduction}

Adult snails of a similar size $(4.078 \pm 0.090 \mathrm{~mm})$ were collected from cultures, shell lengths were measured and the snails were randomly transferred individually to wells containing experimental sediment. The shell lengths were measured every 3 weeks over a 12-week period, and SGRs were calculated as described above. Each week over a 10-week period, when the snails were transferred to new wells, survival was recorded and reproduction was estimated by counting the number of offspring produced per female using a dissecting microscope.

\subsubsection{Feeding rate}

Adult snails in the size range $4.162 \pm 0.133 \mathrm{~mm}$ were collected from cultures and randomly transferred individually to wells with experimental sediment. Feeding rate was measured as the dw of fecal pellets produced per unit time, since nearly all the sediment deposit feeders ingest consists of indigestible mineral grains that pass though the alimentary tract without loss (Lopez and Levinton, 1987). Each week for 6 weeks the fecal pellets from individual adult snails were sieved from the sediment with an $80 \mu \mathrm{m}$ sieve and rinsed with de-ionized water. The pellets were dried at $105^{\circ} \mathrm{C}$ for $24 \mathrm{~h}$ and subsequently weighed.

\subsection{Demographic analysis}

A simple two-stage demographic model was used to determine the population growth rate $(\lambda)$ and to estimate the effects of HHCB at the population level. The two-stage model distinguishes between juvenile and adult life stages and integrates five life-history traits; juvenile and adult survival, reproduction, time to first reproduction and time between reproductive events (Calow et al., 1997).

$F$ is the number of female offspring produced per female per time unit (i.e., per week; in this case averaged for weeks 5-10 of the experiment as explained below), and $p_{\mathrm{j}}$ represents the survival of juveniles between time units from birth to first reproduction. To simplify the mathematics an additional variable is defined, $S_{\mathrm{j}}=p_{\mathrm{j}}^{t_{\mathrm{j}}}$, which represents juvenile survival from birth to age $t_{\mathrm{j}}, S_{\mathrm{a}}$ represents average adult survival between time units, $t_{\mathrm{j}}$ is the time to first reproduction and $t_{\mathrm{a}}$ the time between reproductive events. In this experiment $t_{2}$ was set to 1 week for all treatments since reproduction was measured once a week.

\section{$1=F S_{\mathrm{j}} \lambda^{-t_{\mathrm{j}}}+S_{\mathrm{a}} \lambda^{-t_{\mathrm{a}}}$}

The demographic sensitivities and elasticities of the life-history traits were calculated according to Sibly et al. (2000) to estimate the effect on $\lambda$ of absolute and proportional changes in life-history traits, respectively. The standard error and confidence interval (CI) for $\lambda$ were estimated following Lande (1988) and Sibly et al. (2000). Furthermore, decomposition analyses were carried out to quantify the relative contribution of each of the affected life-history traits to the observed impact on $\lambda$ (Caswell, 1996; Levin et al., 1996).

\subsection{Statistical analyses}

Differences in starting shell length, SGR, average weekly reproduction, average weekly feeding rate, size at first reproduction and time to first reproduction as a function of $\mathrm{HHCB}$ concentration were tested using one-way ANOVA. In cases where significant or marginally significant effects were detected for oneway ANOVA, two-sided Dunnett's tests were performed to compare the con- trol with each of the treatments. For feeding rate a two-way ANOVA was used to test for interaction effects between exposure time and exposure concentration. In the event of no interaction a reduced model (without the interaction term) was used to test whether time and exposure concentration had significant effects on feeding rate. Data are presented as mean $\pm 95 \%$ CI. Values of $\lambda$ were considered to be significantly different if their $95 \%$ CIs did not overlap (Sibly et al., 2000). A significance level of $p \leq 0.05$ is used throughout. $P$-values between 0.05 and 0.1 were defined as marginally significant.

\section{Results}

\subsection{Extraction and spiking efficiencies}

The extraction recoveries of $\mathrm{HHCB}$ for the different treatments are presented in Table 1 . We observed recoveries between $64 \%$ and $86 \%$.

\subsection{Survival}

Adult survival $\left(S_{\mathrm{a}}\right)$ was not affected by $\mathrm{HHCB}$, and all adults survived the entire exposure period. Juvenile survival $\left(S_{\mathrm{j}}\right)$ decreased with increasing $\mathrm{HHCB}$ concentration. One hundred percent of the juveniles exposed to $0,0.1,1$ and $10 \mu \mathrm{g} \mathrm{HHCB} \mathrm{g}{ }^{-1}$ survived from birth to first reproduction. Juvenile survival from birth to first reproduction was $90 \%$ at $30 \mu \mathrm{g} \mathrm{HHCB} \mathrm{g}{ }^{-1}$ and $80 \%$ at $100 \mu \mathrm{g} \mathrm{HHCB} \mathrm{g}{ }^{-1}$.

\subsection{Growth}

SGRs for juvenile and adult snails are shown in Figure 1. The initial average shell lengths were $4.078 \pm 0.090 \mathrm{~mm}$ for adults and

Table 1. Recovery concentrations and recovery (\%) from the extraction of different treatments (mean $\pm \mathrm{SD})$

\begin{tabular}{ccc}
\hline Treatments $\left(\mu \mathrm{g} \mathrm{g}^{-1}\right)$ & Recovery concentrations $\left(\mu \mathrm{g} \mathrm{g}^{-1}\right)$ & Recovery $(\%)$ \\
\hline 0.1 & $0.086 \pm 0.008$ & $86.3 \pm 7.9$ \\
1 & $0.810 \pm 0.048$ & $81.0 \pm 4.8$ \\
10 & $7.0 \pm 0.2$ & $71.8 \pm 3.2$ \\
30 & $19.3 \pm 0.9$ & $64.5 \pm 2.8$ \\
100 & $64.2 \pm 2.0$ & $64.2 \pm 2.0$ \\
\hline
\end{tabular}

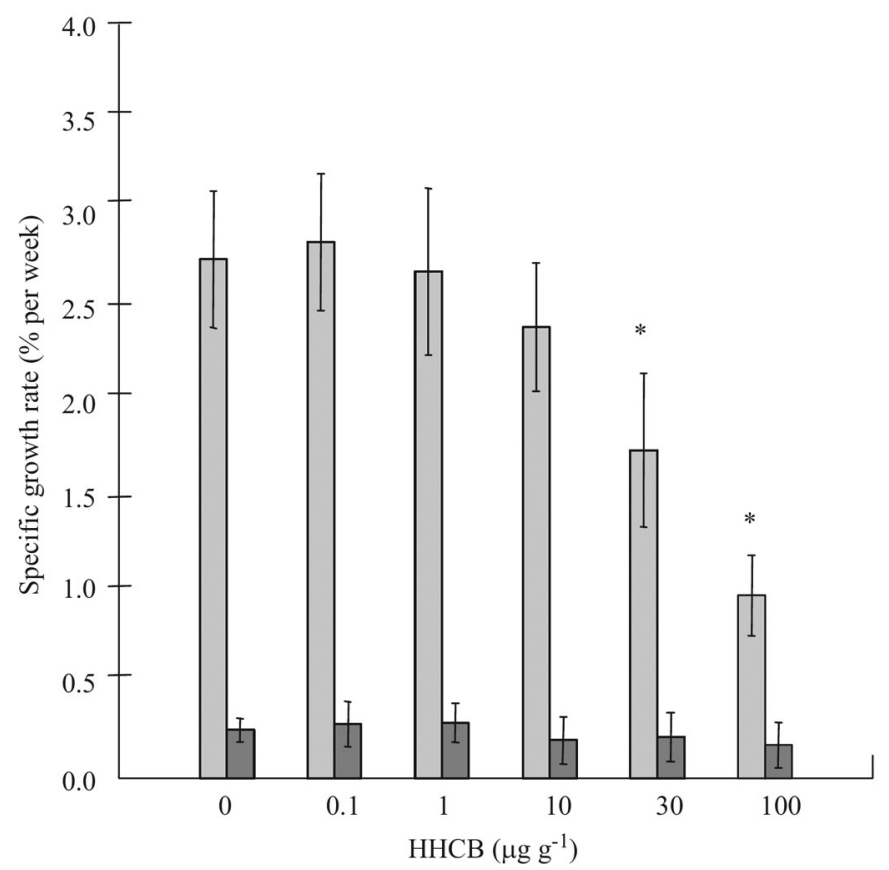

Figure 1. Specific growth rates (SGR) for juvenile (light bars) and adult (dark bars) snails. 


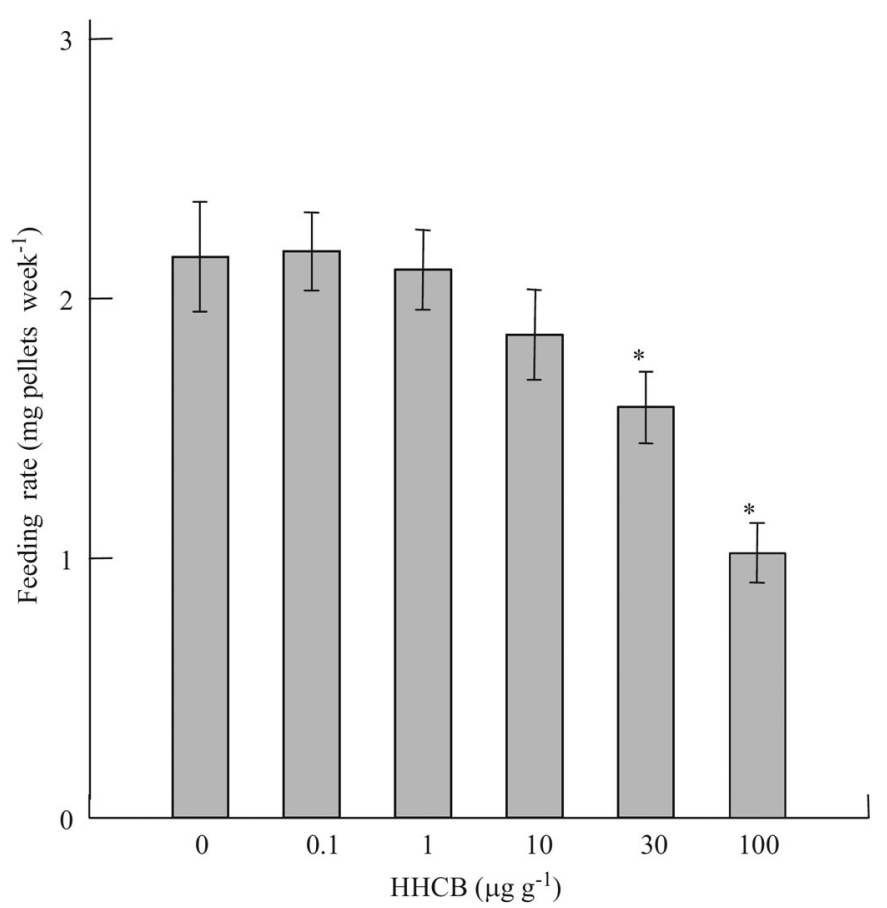

Figure 2. Average adult weekly feeding rates (averaged over all weeks for each snail) for different treatments.

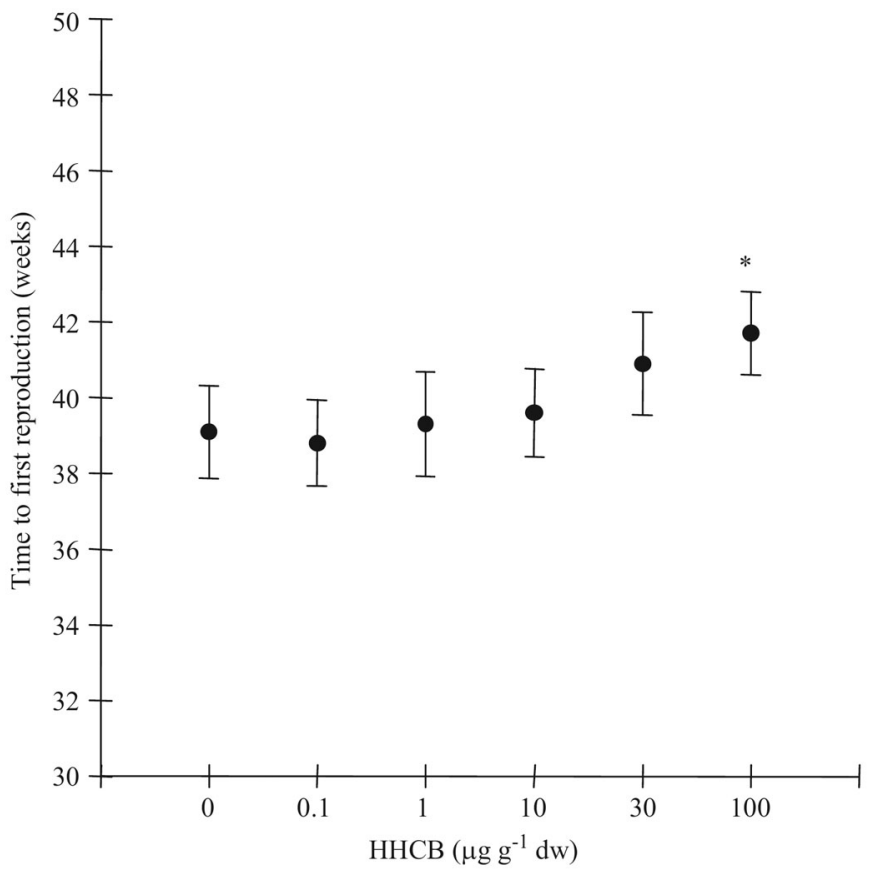

Figure 4. Time to first reproduction $\left(t_{\mathrm{j}}\right)$ as a function of $\mathrm{HHCB}$ concentration.
A
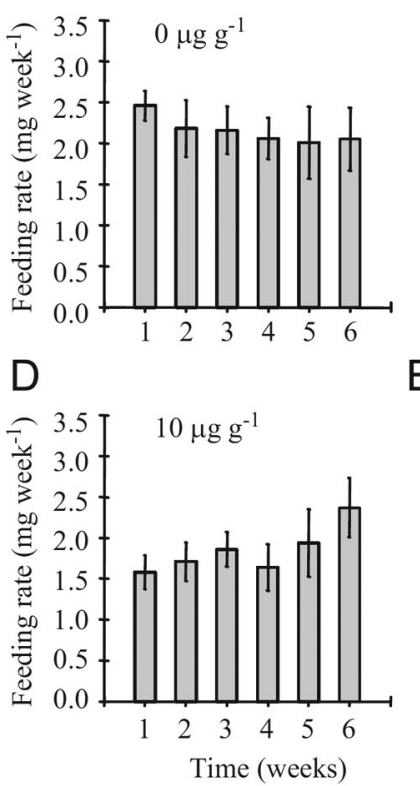

B

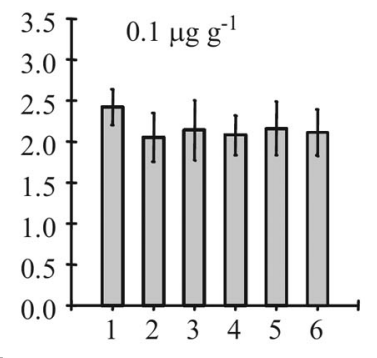

E

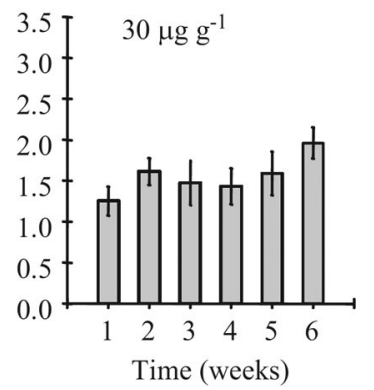

C

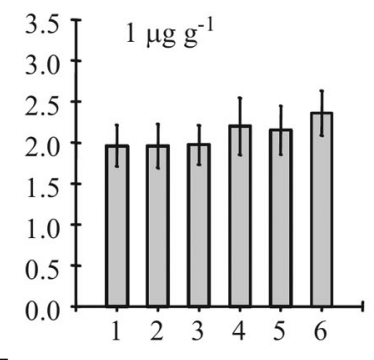

$\mathrm{F}$

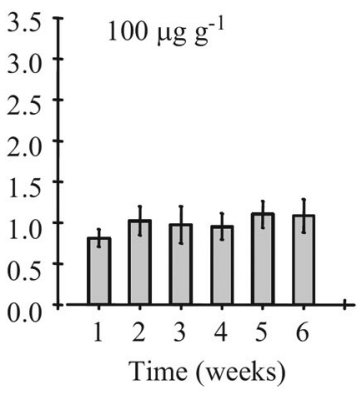

Figure 3. Feeding rates over time in the treatments (A) 0, (B) 0.1 , (C) 1 , (D) 10, (E) 30 and (F) $100 \mu g^{-1}$.

$1.059 \pm 0.099 \mathrm{~mm}$ for juveniles. There were no significant differences in shell length among exposure groups at the start of the experiment for juvenile or adult snails ( $p=0.960 ; p=0.985$, respectively). During 12 weeks of exposure HHCB had no significant effect on adult SGR $(p=0.600)$ but significantly reduced juvenile SGR $(p<0.001)$. Juvenile snails exposed to $30 \mu \mathrm{g} \mathrm{HHCB} \mathrm{g}^{-1}(p<0.001)$ and $100 \mu \mathrm{g} \mathrm{HHCB} \mathrm{g}{ }^{-1}(p<0.001)$ had significantly slower growth rates compared to the control group.

\subsection{Adult feeding rate}

Average adult weekly feeding rates (averaged over all weeks for each snail) for the different treatments are shown in Figure 2. HHCB af- fected average adult feeding rate $(p<0.001)$, which was significantly reduced in snails exposed to $30 \mu \mathrm{g} \mathrm{HHCB} \mathrm{g} \mathrm{H}^{-1}(p<0.001)$ and $100 \mu \mathrm{g} \mathrm{HHCB} \mathrm{g} \mathrm{H}^{-1}(p<0.001)$ compared to the control group.

Feeding rates over time in the different treatments are presented in Figures 3A-F. There was a significant interaction effect between time and exposure concentration on feeding rate, indicating that the response of $P$. antipodarum to $\mathrm{HHCB}$ was time dependent. A graphical comparison among treatments shows that for the control treatment and $0.1 \mu \mathrm{g} \mathrm{HHCB} \mathrm{g}{ }^{-1}$ there appeared to be no change in

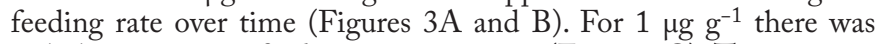
a slight increase in feeding rate over time (Figure 3C). This increase was more apparent at 10 and $30 \mu \mathrm{g} \mathrm{HHCB} \mathrm{g}{ }^{-1}$ (Figures 3D and E). Time did not seem to affect the feeding rate in snails exposed to 
$100 \mu \mathrm{g} \mathrm{HHCB} \mathrm{g}{ }^{-1}$ (Figure 3F). However, the average feeding rate was much lower in these snails compared to the control treatment and snails exposed to lower concentrations of HHCB (Figure 2).

\subsection{Time to first reproduction}

Time to first reproduction $\left(t_{\mathrm{j}}\right)$ as a function of HHCB concentration presented in Figure 4 is significantly affected by HHCB $(p=0.0001)$, and was marginally longer in snails exposed to $30 \mu \mathrm{g} \mathrm{HHCB} \mathrm{g}{ }^{-1}$ $(p=0.078)$ and significantly longer at $100 \mu \mathrm{g} \mathrm{HHCB} \mathrm{g} \mathrm{g}^{-1}(p=0.005)$ compared to the control group.

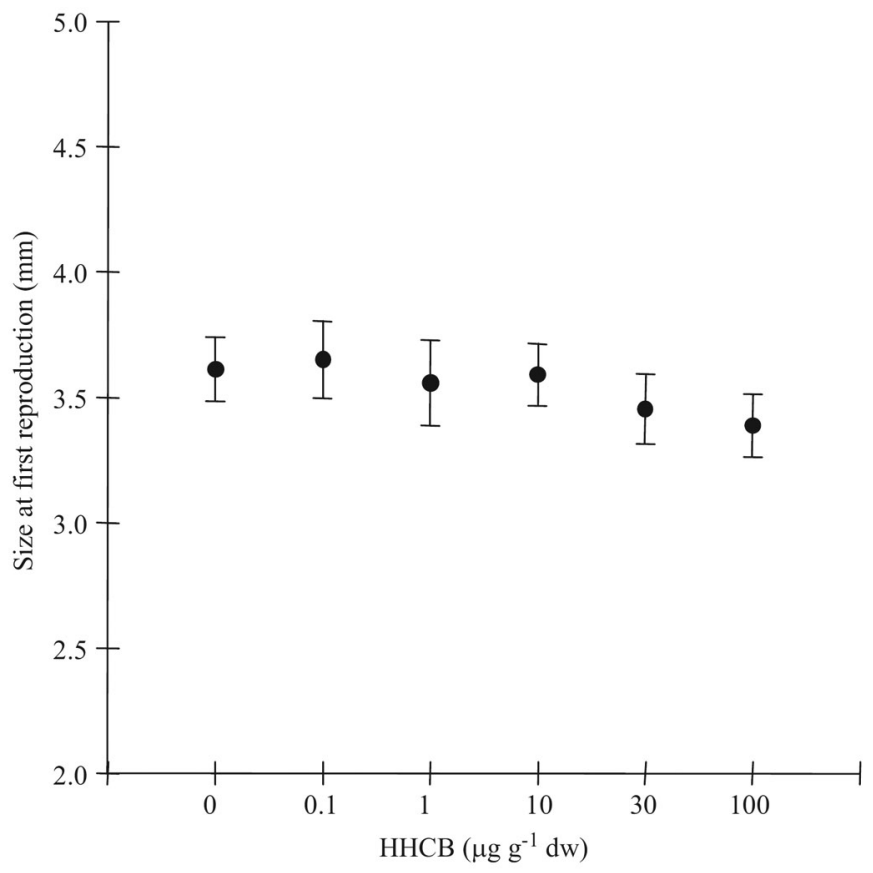

\subsection{Size at first reproduction}

Overall, size at first reproduction seemed to decrease with increasing HHCB concentration (Figure 5). However, this effect was only marginally significant $(p=0.051)$ and it was only snails in the highest HHCB concentration that differed marginally from the control group $(p=0.075)$. There were no significant differences in size between the other exposure groups and the control snails $($ all $p>0.1)$.

\subsection{Reproduction}

The relationship between reproductive output and $\mathrm{HHCB}$ exposure over time (i.e., 10 weeks) is presented in Figures 6A-F. It appears that there is a decline in reproduction over time, but the pattern is not very clear. However, looking at the graphs for each HHCB treatment (Figures 6A-F), it seems that reproduction on average is higher during the first 4 weeks compared to the last 6 weeks especially for snails exposed to the higher HHCB concentrations. P. antipodarum is ovoviviparous, and the duration of the embryonic stage is $30-35$ days at $15{ }^{\circ} \mathrm{C}$ (Dorgelo, 1991). Therefore the first four experimental weeks represent juveniles that developed prior to the start of the experiment. We therefore chose to analyze the data for the first 4 weeks and the remaining 6 weeks separately. Whereas there were no among-treatment differences in reproduction during the first 4 weeks of exposure $(p=0.724)$, a significant effect was detected $(p=0.043)$ on reproductive output averaged over the last 6 weeks (Figure 7). Reproduction was significantly reduced at $10(p=0.028), 30(p=0.004)$ and $100(p=0.001) \mu \mathrm{g} \mathrm{HHCB} \mathrm{g}{ }^{-1} \mathrm{dw}$ sediment compared to the control group.

\subsection{Population growth rate}

For all treatments the population growth rate $(\lambda)$ was greater than one, which indicates a population increasing in size (Figure 8); $\lambda$ slightly decreased with increasing $\mathrm{HHCB}$ concentration,

Figure 5. Size at first reproduction vs HHCB concentration.

A

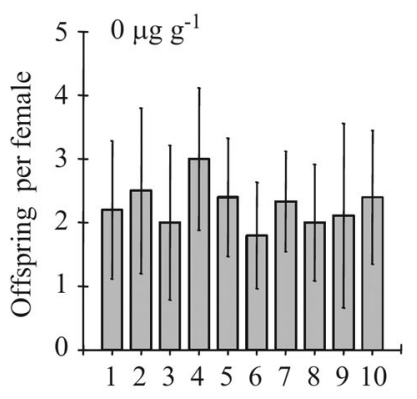

D

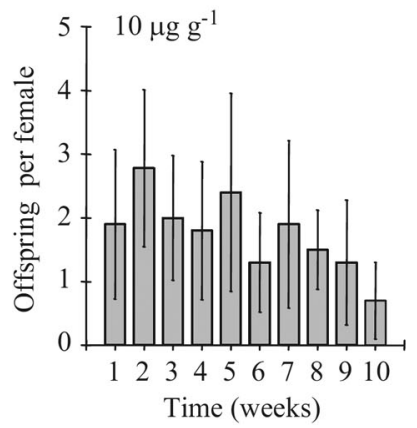

B

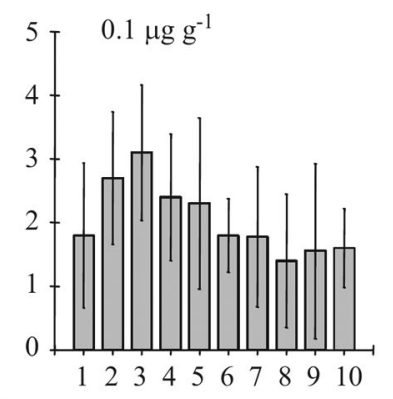

E

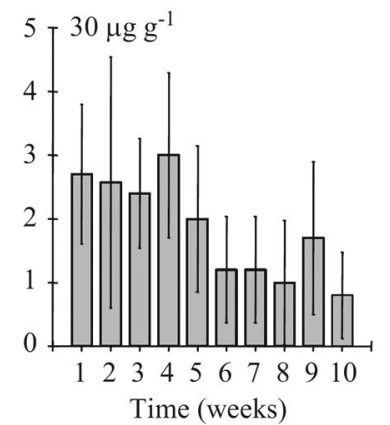

C

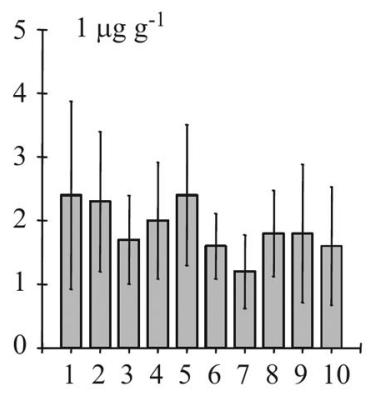

$\mathrm{F}$

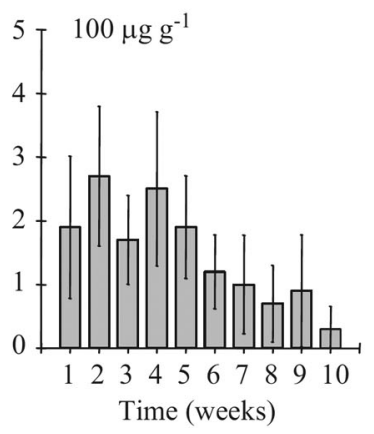

Figure 6. Relationship between reproductive output and HHCB exposure over time: (A) 0, (B) 0.1, (C) 1, (D) 10, (E) 30 and (F) $100 \mu \mathrm{g} \mathrm{g}^{-1}$. 


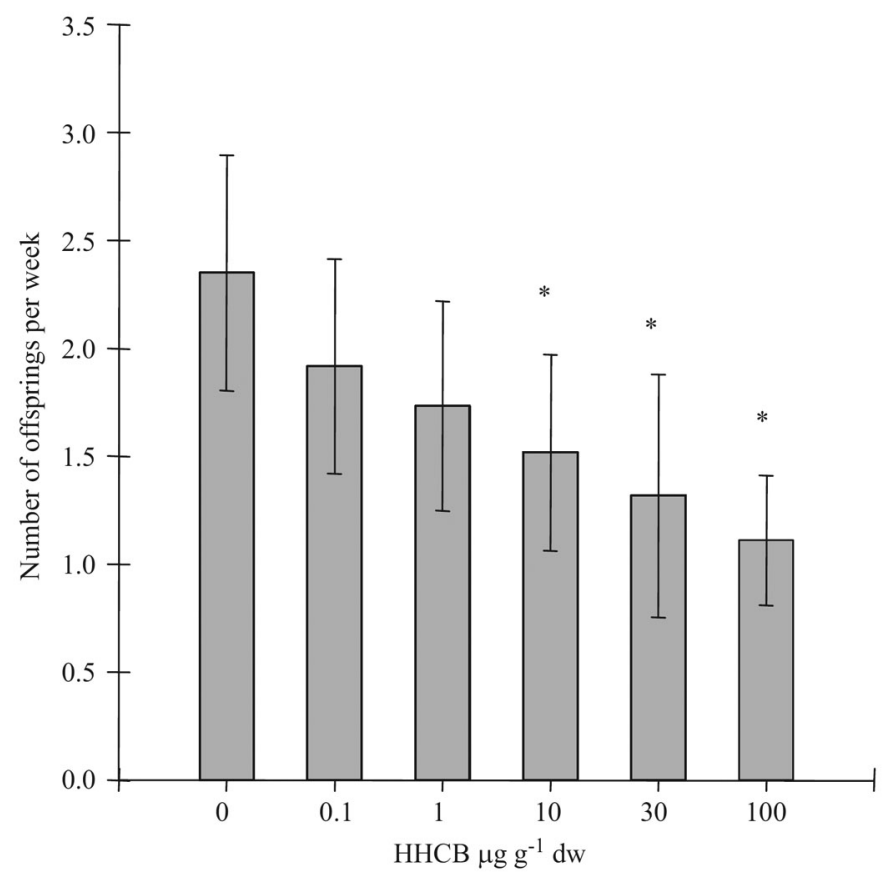

Figure 7. Reproductive output, averaged for weeks 5-10, vs HHCB concentration.

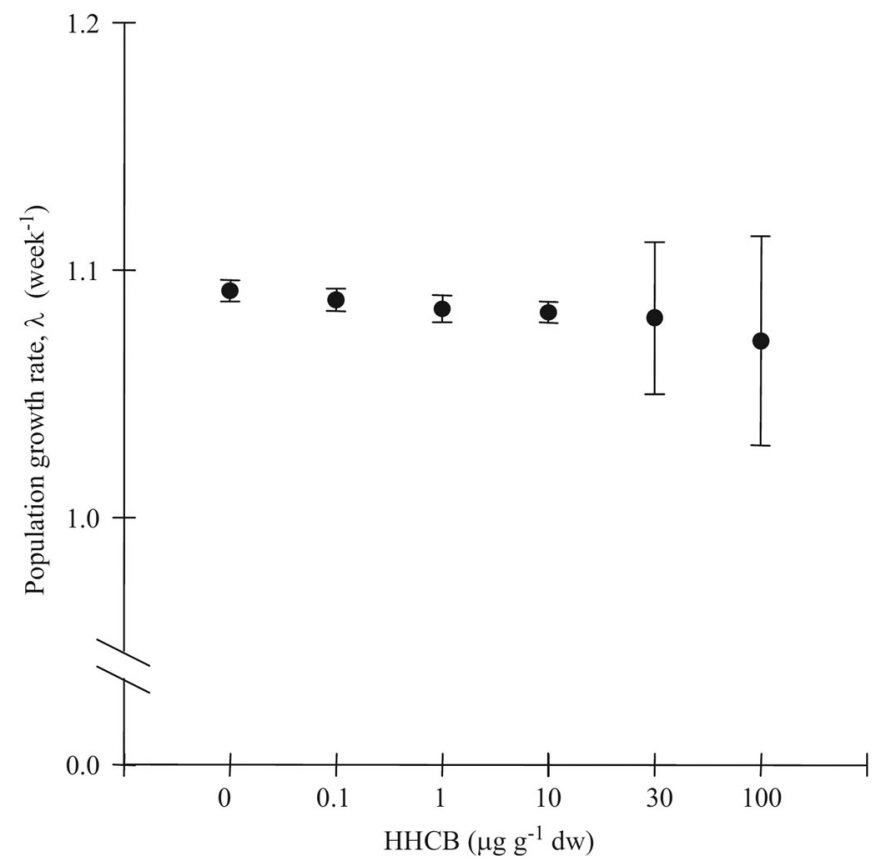

Figure 8. Population growth rate vs HHCB concentration.

with the highest mean value in the control group $(\lambda=1.092$ at $0 \mu \mathrm{g} \mathrm{HHCB} \mathrm{g}^{-1}$ ) and the lowest in snails exposed to $100 \mu \mathrm{g} \mathrm{HHCB} \mathrm{g}{ }^{-1}(\lambda=1.071)$, a difference of $1.85 \%$. However, using the overlap of the $95 \%$ CIs around $\lambda$ to estimate significance, following Sibly et al. (2000), the slight differences in $\lambda$ among treatments were not significant. Therefore a NOEC for $\lambda$ could not be estimated, but is greater than the highest exposure concentration of $100 \mu \mathrm{g} \mathrm{HHCB} \mathrm{g}{ }^{-1}$.

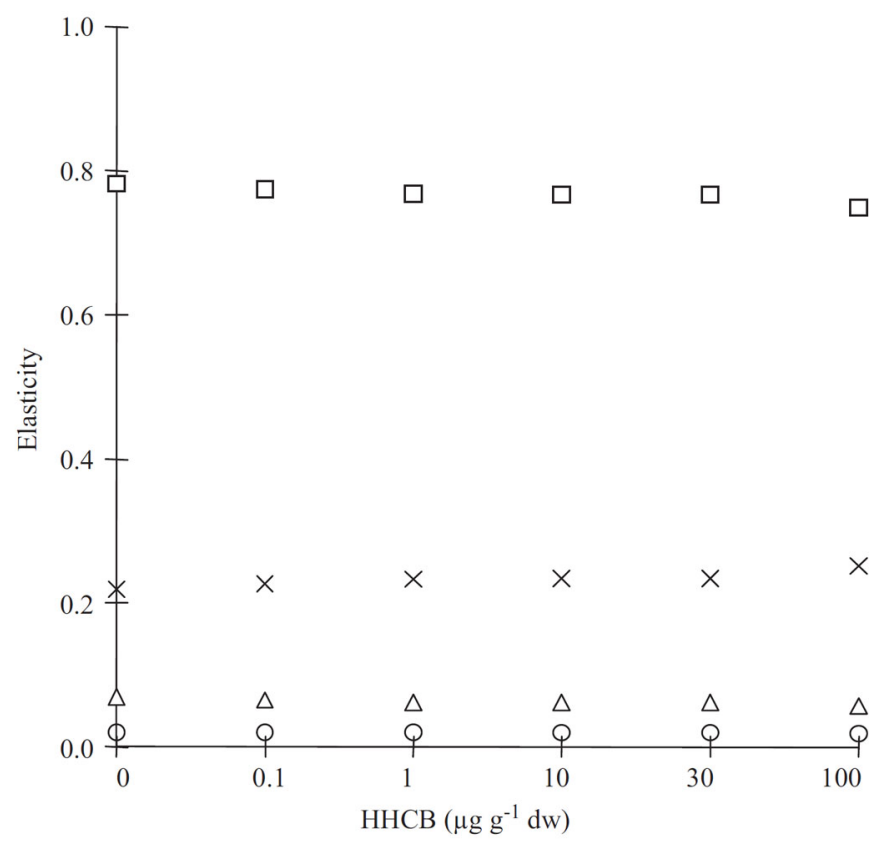

Figure 9. Elasticity vs HHCB concentration. Squares are $S_{\mathrm{j}}$, crosses are $S_{\mathrm{a}}$, Triangles are $t_{\mathrm{j}}$ and circles are $F$.

\subsection{Elasticity}

The elasticity analysis showed that population growth rate was several times more sensitive to relative changes in juvenile survival than to changes in the other life-history parameters (Figure 9). The life-cycle trait having the second highest elasticity was adult survival followed by time to first reproduction and fecundity, in that order. There was no notable change in the elasticity patterns among treatments.

\subsection{Decomposition}

The proportional contributions of fecundity $(F)$, time to first reproduction $\left(t_{\mathrm{j}}\right)$, juvenile survival $\left(p_{\mathrm{j}}\right)$ and adult survival $\left(S_{\mathrm{a}}\right)$ to the observed effect on $\lambda$ are shown in Figure 10.

Decomposition analysis showed that for all treatments the largest proportional contribution to the (non-significant) change in population growth rate $(\lambda)$ was from fecundity. In snails exposed to $0.1,1$ and $10 \mu \mathrm{g} \mathrm{HHCB} \mathrm{g}^{-1}$ there was a small contribution from time to first reproduction (which was positive in the $0.1 \mu \mathrm{g} \mathrm{HHCB} \mathrm{g}{ }^{-1}$ treatment because time to first reproduction was shorter). For 30 and $100 \mu \mathrm{g} \mathrm{HHCB} \mathrm{g}{ }^{-1}$, fecundity, time to first reproduction and juvenile survival contributed to the changes in $\lambda$. As there were no effects of HHCB on adult survival, the contribution of $S_{\mathrm{a}}$ to changes in $\lambda$ was zero.

\section{Discussion}

\subsection{Sediment concentrations of $\mathrm{HHCB}$}

Our recoveries of HHCB are similar to those reported in other studies. Difrancesco et al. (2004) found soil extraction efficiency to be $87 \pm 9 \%$ and leachate efficiency to be $79 \pm 9 \%$. Simonich et al. (2000) found a recovery of $68.2 \pm 12.4 \%$ for active sludge and $85.1 \pm 0.4 \%$ for influent solids. 


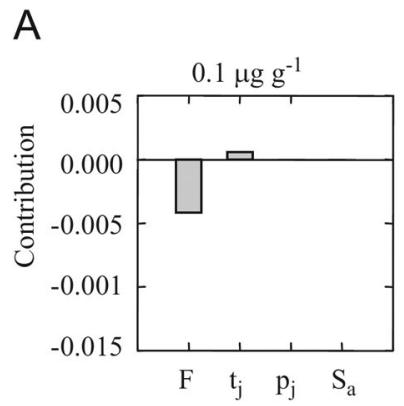

B

C
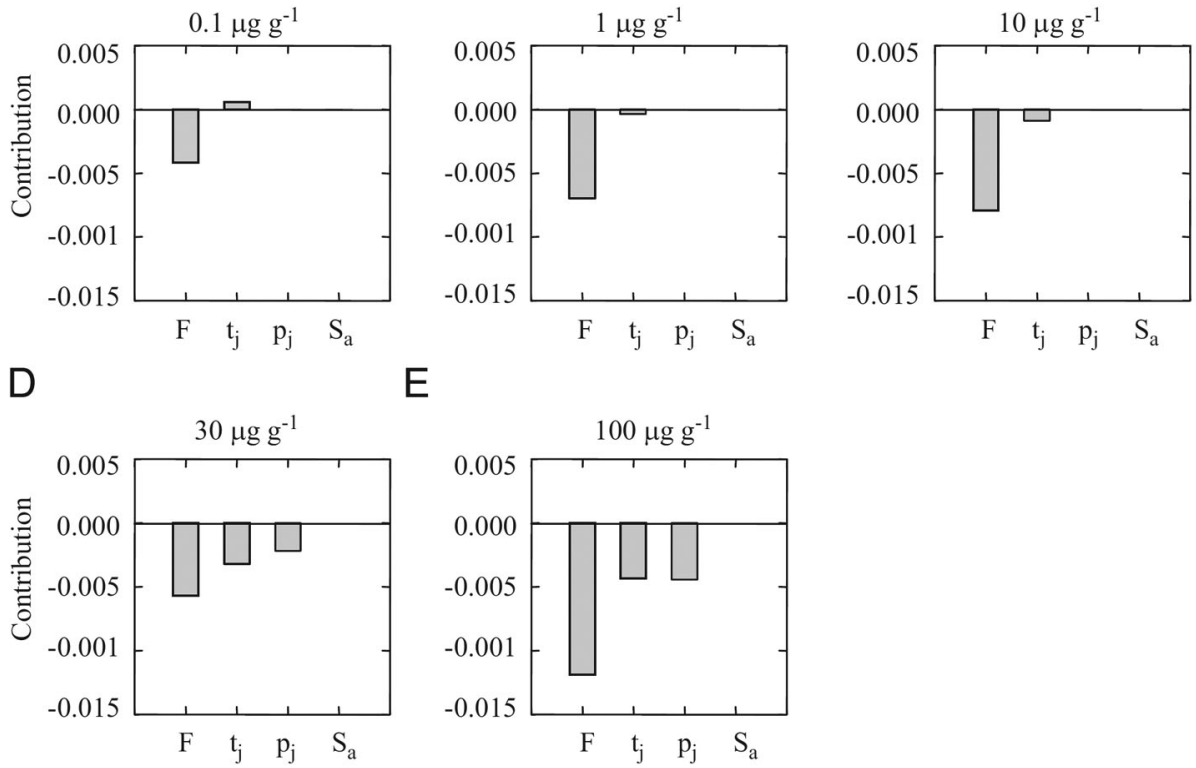

$E$

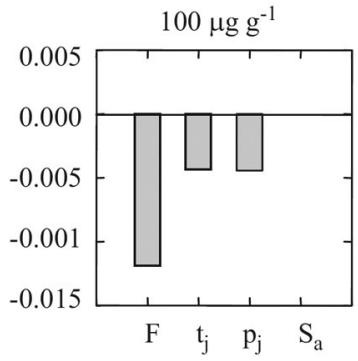

Figure 10. Proportional contributions of fecundity $(F)$, time to first reproduction $\left(t_{\mathrm{j}}\right)$, juvenile survival $\left(p_{\mathrm{j}}\right)$ and adult survival $\left(S_{\mathrm{a}}\right)$ to the observed effect on $\lambda$ at an HHCB concentration of (A) 0.1, (B) 1, (C) 10, (D) 30 and (E) $100 \mu \mathrm{g} \mathrm{g}^{-1}$.

\subsection{Effects of HHCB at the individual level}

Adult survival was $100 \%$ in all treatments, whereas juvenile survival was reduced at 30 and $100 \mu \mathrm{g} \mathrm{HHCB} \mathrm{g}{ }^{-1}$ (by $10 \%$ and $20 \%$, respectively). Of the remaining traits, reproduction (averaged from 5 to 10 weeks of exposure) was the most sensitive (affected at $10 \mu \mathrm{g} \mathrm{HHCB} \mathrm{g}^{-1}$ ) followed by adult feeding rate and juvenile growth

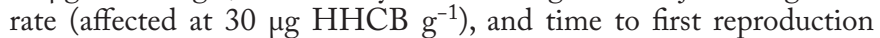
(marginally affected at $30 \mu \mathrm{g} \mathrm{HHCB} \mathrm{g}^{-1}$ ). The least sensitive traits were adult growth rate (not affected) and size at first reproduction (marginally affected at $100 \mu \mathrm{g} / \mathrm{g}$ ).

For the control group, average reproduction was $2.6( \pm 0.6) \mathrm{ju}-$ veniles per female per week. This value is in good agreement with data reported from other studies (Jacobsen and Forbes, 1997; Jensen et al., 2001). The mean value for time to first reproduction in the control group was 39 weeks, whereas Jensen et al. (2001) found an average time to first reproduction of approximately 35 weeks under similar laboratory conditions. The mean value for size at first reproduction was $3.6 \mathrm{~mm}$ for the control group, compared to 4.2-4.7 $\mathrm{mm}$ reported by Jensen et al. (2001). The slightly slower growth in the present study is likely due to the fact that snails were maintained in the dark, whereas Jensen et al. (2001) maintained snails under a $12 \mathrm{~h}$ light:12 h dark cycle, which would have allowed growth of benthic microalgae, a preferred food source for $P$. antipodarum.

HHCB exposure significantly reduced juvenile growth at 30 and $100 \mu \mathrm{g} \mathrm{HHCB} \mathrm{g}{ }^{-1}$ but did not affect adult growth. This may be explained by either a higher sensitivity of juveniles to the chemical or by the minimal growth rate of adult snails compared to juveniles or both.

Average adult feeding rate per week was significantly reduced by $\mathrm{HHCB}$ exposures of 30 and $100 \mu \mathrm{gHCB} \mathrm{g} \mathrm{H}^{-1}$, and there was a significant interaction between time and exposure concentration on feeding rate, such that there appeared to be an increase in feeding rate with time for the 1,10 and $30 \mu \mathrm{g} \mathrm{HHCB} \mathrm{g}{ }^{-1}$, suggesting that snails may have acclimated to $\mathrm{HHCB}$ exposure. Feeding rate in the $100 \mu \mathrm{g} \mathrm{HHCB} \mathrm{g}{ }^{-1}$ did not increase with time and was, on average, lower than in the control group.
Table 2. Percentage differences between the control treatment and HHCB treatments for different life-history traits and $\lambda$

\begin{tabular}{lrrrrr}
\hline Treatment $\left(\mu \mathrm{g} \mathrm{g}^{-1}\right)$ & \multicolumn{1}{c}{0.1} & \multicolumn{1}{c}{1} & \multicolumn{1}{c}{10} & \multicolumn{1}{c}{30} & \multicolumn{1}{c}{100} \\
\hline$F$ & -17.37 & -27.41 & -30.50 & -23.55 & -42.86 \\
$t_{\mathrm{j}}$ & 0.77 & -0.51 & -1.28 & -4.60 & -6.65 \\
$S_{\mathrm{a}}$ & 0.00 & 0.00 & 0.00 & 0.00 & 0.00 \\
$p_{\mathrm{j}}$ & 0.00 & 0.00 & 0.00 & -0.26 & -0.53 \\
$\lambda$ & -0.33 & -0.66 & -0.80 & -1.01 & -1.85 \\
\hline
\end{tabular}

Although adult snails in 1,10 and $30 \mu \mathrm{g} \mathrm{HHCB} \mathrm{g}{ }^{-1}$ treatments initially showed somewhat lower feeding rates compared to the control, feeding rates returned to similar levels as those of the control group by the end of the experiment. This may suggest that snails exposed to intermediate concentrations of $\mathrm{HHCB}$ acclimated to the exposure after a few weeks. The reduced feeding rates during the first few weeks of the experiment may help to explain the reduction in average reproductive output during weeks 5-10 and are consistent with the observed reduction in juvenile growth rate in the two highest exposure treatments.

\subsection{Effects of $H H C B$ at the population level}

Population growth rate $(\lambda)$ was greater than one for all treatments, which is characteristic of a growing population, and was reduced by $1.9 \%$ at the highest exposure concentration compared to the control (Table 2). For the control group the mean population growth rate was 1.092. This is close to the mean population growth rate reported by Jensen et al. (2001) of approximately 1.102 for this species under similar laboratory conditions.

The increasing variability in $\lambda$ at the two highest concentrations (i.e., 30 and $100 \mu \mathrm{g} \mathrm{g}^{-1}$; Figure 8 ) is due to the fact that the contribution of the standard error in $p_{\mathrm{j}}$ to the standard error in $\lambda$ (calculated as $\sqrt{\left[p_{\mathrm{j}}\left(1-p_{\mathrm{j}}\right) / n\right]}$, following Sibly et al., 2000) was zero for the $0,0.1,1$, and $10 \mu \mathrm{g} \mathrm{HHCB} \mathrm{g}{ }^{-1}$ treatments (since juvenile survival was $100 \%)$, whereas for 30 and $100 \mu \mathrm{g} \mathrm{HHCB} \mathrm{g-1}$ there was $90 \%$ 
and $80 \%$ juvenile survival, respectively, and a corresponding nonzero contribution of the standard error in $p_{\mathrm{j}}$ to the standard error in $\lambda$. Due to a relatively high demographic sensitivity of $p_{\mathrm{j}}$, this trait contributes a great deal to the analytically calculated CI for $\lambda$ (Sibly et al., 2000).

Whereas fecundity was the most sensitive of the individual traits to HHCB exposure, the elasticity analysis demonstrated that this trait was the least sensitive demographically. This means that a given proportional change in fecundity will have much less of an impact on population growth rate than the same proportional change in the other life-history traits. In contrast, juvenile survival had the highest elasticity of all traits, followed by adult survival and time to first reproduction, and all three traits were less sensitive to HHCB exposure than fecundity. This is a common pattern in demographic studies (Pfister, 1998), in which it has been shown for a wide range of taxa that fecundity is generally more sensitive to environmental variability than either survival or growth, and that fecundity likewise has a lower elasticity than these other life-history traits. It has been proposed that this is the result of natural selection altering life histories to minimize life-history stages with both high demographic sensitivity and high variation since variability in population growth rate is thought to have negative consequences for organism fitness (Pfister, 1998). This may have interesting implications for the choice of toxicity test endpoints and for extrapolating these to ecologically relevant impacts.

Whereas elasticity analysis provides insight into the potential importance of changes in life-history traits for population dynamics (i.e., it asks if a life-history trait changes by a given proportion then what would be the corresponding proportional change in $\lambda$, all else being equal), decomposition analysis is critical for understanding the mechanisms underlying the observed impacts on $\lambda$ in a particular environmental setting. For example, despite its high elasticity, juvenile survival made no contribution to the observed change in $\lambda$ at the lowest concentrations (i.e., $0.1,1$, and $10 \mu \mathrm{g} \mathrm{g}^{-1}$ ), a very small contribution at $30 \mu \mathrm{g} \mathrm{HHCB} \mathrm{g}{ }^{-1}$ and a slightly higher contribution at $100 \mu \mathrm{g}$ HHCB g ${ }^{-1}$. This is because juvenile survival was only minimally affected by HHCB (if it had been more affected, the impact on $\lambda$ would have been substantial). Whereas fecundity had the lowest elasticity, it nevertheless made the largest proportional contribution to the (non-significant) impact on $\lambda$ because it was so much more sensitive to HHCB compared to the other lifehistory traits.

Because of the relatively long life cycle of $P$. antipodarum, we decided to run the juvenile and adult exposures in parallel (i.e., using different individuals). This could potentially have resulted in an underestimation of effects on the adult stage. For example, we observed reduced juvenile growth rates at the highest exposure concentrations. This could have resulted in a reduced fecundity compared to individuals first exposed as adults, and/or a reduced survival of adults. However, given the low elasticities of both fecundity and adult survival, we do not believe that our design resulted in a large underestimation of population-level impacts.

\subsection{Comparison of individual-and population-level effects}

If we compare the percentage differences between the control treatment and $\mathrm{HHCB}$ treatments for each life-history trait and $\lambda$ (Table 2) it is apparent that effects of HHCB on sensitive individual-level endpoints are attenuated at the population level. For all the treatments the highest percentage impacts were on fecundity, and these increased with increasing concentration (from 17\% at $0.1 \mu \mathrm{g} \mathrm{HHCB} \mathrm{g} \mathrm{g}^{-1}$ to $43 \%$ at $100 \mu \mathrm{g} \mathrm{HHCB} \mathrm{g}{ }^{-1}$ ). There were some differences in time to first reproduction following the same pattern as fecundity. Juvenile survival $\left(p_{\mathrm{j}}\right)$ showed no difference at the lowest concentrations but a slight percentage difference at 30 and $100 \mu \mathrm{g} \mathrm{HHCB} \mathrm{g}{ }^{-1}$. For population growth rate $(\lambda)$ there were only small differences between the control treatment and HHCB treatments, but these differences increased with increasing expo- sure concentrations (from $0.33 \%$ at $0.1 \mu \mathrm{g} \mathrm{HHCB} \mathrm{g} \mathrm{H}^{-1}$ to $1.85 \%$ at $100 \mu \mathrm{g} \mathrm{HHCB} \mathrm{g}^{-1}$ ). Assessing likely impacts on population growth rate from impacts on single individual-level endpoints can result in underestimates or overestimates. For example, if juvenile and adult survival were the only traits measured in this case, the expected impact for the population would have been slightly underestimated. In contrast, basing the assessment on fecundity alone would substantially overestimate likely impacts on populations. A similar pattern has been observed in other laboratory experiments on other chemicals with terrestrial and aquatic invertebrates ( Hansen et al., 1999a,1999b; Linke-Gamenick et al., 1999; Jensen et al., 2001; Widarto et al., 2004). But the extent to which, and under what conditions, impairments in fecundity are generally likely to overestimate impacts on population dynamics are questions in need of further attention.

\subsection{Extending the analysis to ecologically realistic conditions}

It is important to emphasize that the approach used here cannot (and does not intend to) make predictions about actual population sizes under different exposure conditions at some future time point. Nor does it include many additional ecological complexities that may be important in an actual field situation. Nevertheless simple models of the kind employed here provide valuable information about the robustness of a population, summarizing its capacity for future growth, and the relative importance of changes in life-history traits on population dynamics (Ferson et al., 1996; Caswell, 2001). A potential criticism of the approach used in the present study is that it was conducted under favorable laboratory conditions in which snails were not subject to competition or predation and in which population growth rate was greater than one. There are concerns that under more ecologically realistic conditions populations may be more susceptible to toxic chemicals because their life-history traits are impacted by other stressors. One possible way to address such concerns is to adjust the values of the life-history traits of control snails toward more field-realistic values, to assume the same proportional impacts of HHCB on individual life-history traits, and to recalculate expected impacts on population growth rate. We did this for the present data by considering three more ecologically realistic scenarios (Table 3). In Scenario 1 we reduced survival of juvenile snails in the control group to $10 \%$ and kept all other traits unchanged. In Scenario 2, we reduced survival of juvenile snails to $10 \%$ and reduced survival of adult snails to $80 \%$. Scenario 3 was as Scenario 2, but here we also reduced fecundity by $50 \%$ in the control group snails. Table 3 shows how $\lambda$ changes for each of these scenarios, with Scenarios 2 and 3 approximating a $\lambda$ of one, which is the expected long-term average for stable field populations. Next we calculated life-history trait values for each HHCB exposure concentration, assuming that the traits showed the same proportional change (i.e., were equally as sensitive to $\mathrm{HHCB}$ ) as in our experimental treatments. Figures $11 \mathrm{~A}-\mathrm{D}$ show the results of elasticity analyses for each of the scenarios compared to the experimental results. This analysis shows that as the life-history traits are altered to more ecologically realistic values, their elasticity patterns

Table 3. Values for life-history traits and population growth rate measured in the laboratory control group and as they were adjusted for the three scenarios Traits that were changed relative to the laboratory control in each scenario are shown in bold.

\begin{tabular}{lllll}
\hline Trait in Control & Laboratory & Scenario 1 & Scenario 2 & Scenario 3 \\
\hline$F$ & 2.59 & 2.59 & 2.59 & $\mathbf{1 . 3 0}$ \\
$S_{\mathrm{j}}$ & 1 & $\mathbf{0 . 1}$ & $\mathbf{0 . 1}$ & $\mathbf{0 . 1}$ \\
$S_{\mathrm{a}}$ & 1 & 1 & $\mathbf{0 . 8}$ & $\mathbf{0 . 8}$ \\
$t_{\mathrm{j}}$ & 39.1 & 39.1 & 39.1 & 39.1 \\
$t_{\mathrm{a}}$ & 1 & 1 & 1 & 1 \\
$\lambda$ & 1.0917 & 1.0463 & 1.0060 & 0.9901 \\
\hline
\end{tabular}


A
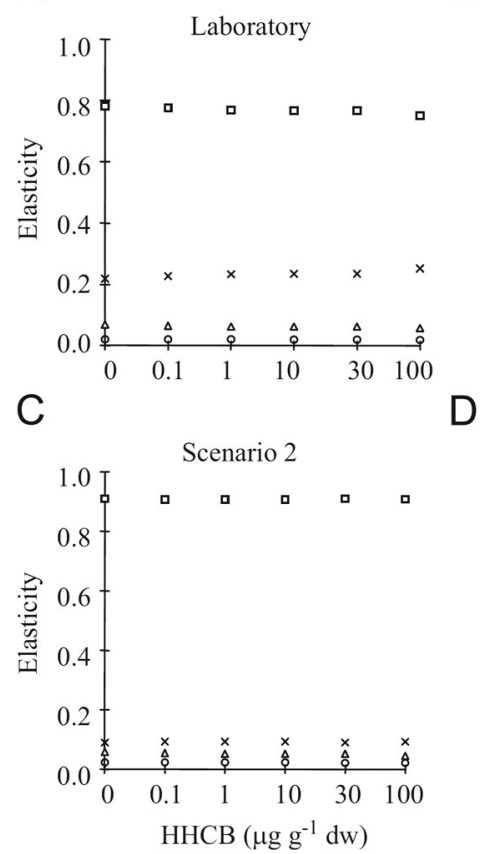

B
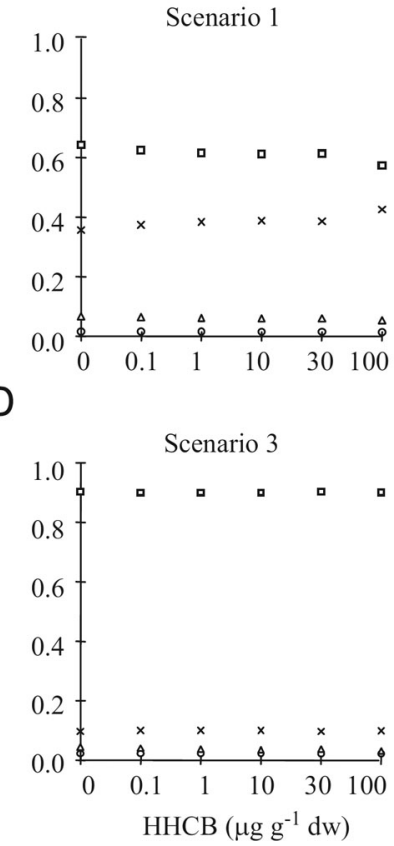

Figure 11. Results of elasticity analyses for (A) laboratory conditions and (B)-(D) Scenarios 1-3, respectively. Squares are $S_{\mathrm{j}}$, crosses are $S_{\mathrm{a}}$, Triangles are $t_{\mathrm{j}}$ and circles are $F$.

Table 4. Calculated effects of HHCB on $\lambda$ measured under laboratory conditions and in the three scenarios described in Table 3

\begin{tabular}{lllll}
\hline $\operatorname{HHCB}\left(\mu \mathrm{g} \mathrm{g}^{-1}\right)$ & Laboratory & Scenario 1 & Scenario 2 & Scenario 3 \\
\hline 0 & 1.0917 & 1.0463 & 1.0060 & 0.9901 \\
0.1 & 1.0881 & 1.0432 & 1.0016 & 0.9855 \\
1 & 1.0844 & 1.0407 & 0.9986 & 0.9828 \\
10 & 1.0830 & 1.0398 & 0.9976 & 0.9819 \\
30 & 1.0807 & 1.0389 & 0.9974 & 0.9822 \\
100 & 1.0714 & 1.0324 & 0.9886 & 0.9739 \\
Max. \% reduction & 1.85 & 1.33 & 1.73 & 1.64 \\
\hline
\end{tabular}

The maximum percentage reduction in $\lambda$ (for the $100 \mu \mathrm{g} \mathrm{g}{ }^{-1}$ treatment) is shown in the bottom row.

change. For example, when juvenile survival is reduced, keeping all else equal, its elasticity reduces and the elasticity of adult survival increases (Figure 11B). Of the most importance, however, is that in none of the scenarios is the effect of $\mathrm{HHCB}$ on $\lambda$ greater than in the laboratory experimental system (Table 4). This suggests that population-level impacts calculated from our laboratory measurements are a fairly robust indicator of likely impacts of $\mathrm{HHCB}$ on populations of $P$. antipodarum under more realistic field conditions. But clearly, this scenario approach is limited in that it does not consider all potential ecological complexities that might occur in the field.

\section{Conclusion}

In conclusion, life-table response experiments in combination with simple demographic models can provide a powerful tool for interpreting the responses of organisms at the individual level in terms of

likely impacts on population dynamics. Our analyses showed that fecundity was the most sensitive individual-level endpoint to HHCB exposure, but that the relatively large impact on this trait was not reflected in a correspondingly large impact on population growth rate, which is in keeping with expectations based on evolutionary theory. Sediment concentrations of HHCB in the field have been reported to occur in the range of $0.002-2.2 \mu \mathrm{g} \mathrm{g}^{-1} \mathrm{dw}$ sediment. Comparison of these exposure concentrations to the results of the present study suggests that populations of $P$. antipodarum are unlikely to be at risk from HHCB exposure under natural field conditions.

Acknowledgments - We wish to thank P. Christensen and L. Maarup for technical assistance and P. Calow and F. Balk for comments on the written manuscript. This study was funded by a grant from the Research Institute for Fragrance Materials to V.F.

\section{References}

Akçakaya et al., 2008 , H. R. Akçakaya, J. D. Stark, T. S. Bridges (Eds.), Demographic Toxicity: Case Studies in Ecological Risk Assessment, Oxford University Press, Oxford, UK (2008)

Balk and Ford, 1999a F. Balk, R. A. Ford, Environmental risk assessment for the polycyclic musks AHTN and HHCB in the EU: I. Fate and exposure assessment, Toxicol. Lett., 111 (1-2) (1999), pp. 57-79

Balk and Ford, 1999b F. Balk, R. A. Ford, Environmental risk assessment for the polycyclic musks, AHTN and HHCB: II. Effect assessment and risk characterisation, Toxicol. Lett., 111 (1-2) (1999), pp. 81-94

Balk et al., 2004 F. Balk, D. Salvito, H. Blok, The role of musk and musk compounds in the fragrance industry, G. Rimkus (Ed.), Synthetic Musk Fragrance in the Environment, The Handbook of Environment Chemistry, Springer, Berlin (2004)

Barnthouse et al., 2008 L. W. Barnthouse, W. R. Munns Jr., and M. T. Sorensen, eds., 2008. Population-Level Ecological Risk Assessment. CRC Taylor \& Francis, Boca Raton, FL, USA.

Berset et al., 2004 J. D. Berset, T. Kupper, R. Etter, J. Tarradellas, Considerations about the enantioselective transformation of polycyclic musks in wastewater, treated wastewater and sewage sludge and analysis of their fate in a sequencing batch reactor plant, Chemosphere, 57 (8) (2004), pp. 987-996

Bester, 2005 K. Bester, Polycyclic musks in the Ruhr catchment areatransport, discharges of waste water, and transformation of $\mathrm{HHCB}$, AHTN and HHCB-lactone, J. Environ. Monitor., 7 (2005), pp. 43-51

Bester et al., 1998 K. Bester, H. Hühnerfuss, W. Lange, G. G. Rimkus, and $\mathrm{N}$. Theobald, Results of non-target screening of lipophilic organic pollutants in the German bight II: Polycyclic musk fragrances, Water Res., 32 (6) (1998), pp. 1857-1863

Calow et al., 1997 P. Calow, R. Sibly, V. Forbes, Risk assessment on the basis of simplified life-history scenarios, Environ. Toxicol. Chem., 16 (9) (1997), pp. 1983-1989

Caswell, 1996 H. Caswell, Demographic meets ecotoxicology: Untangling the population level effects of toxic substances, in M. C. Newman and C. H. Jagoe, eds., Ecotoxicology: A Hierarchical Treatment, Lewis publishers (1996) (Chapter 9)

Caswell, 2001 H. Caswell, Matrix Population Models (2nd edition), Sinauer Associates, Inc., Sunderland (2001)

Dahl and Winter, 1993 A. Dahl and B. L. Winter, Life-history and growth of the Prosobranch snail Potamopyrgus jenkinsi in Lake Esrom, Denmark, Ver. Int. Verein. Limnol., 25 (1993), pp. 582-586

DiFrancesco et al., 2004 A. M. DiFrancesco, P. C. Chiu, L. J. Standley, H. E. Allen, and D. T. Salvito, Dissipation of fragrance materials in sludgeamended soils, Environ. Sci. Technol., 38 (1) (2004), pp. 194-201

Dorgelo, 1991 J. Dorgelo, Growth food and respiration in the prosobranch snail Potamopyrgus jenkinsi (E. A. Smith) (Hydrobiidae, Mollusca), Ver. Int. Verein. Limnol., 24 (1991), pp. 2947-2953

Dsikowitzky et al., 2002 L. Dsikowitzky, J. Schwarzbauer, and R. Littke, Distribution of polycyclic musks in water and particulate matter of the Lippe River (Germany), Org. Geochem., 33 (12) (2002), pp. 1747-1758 
EC, 2003 European Commission, 2003. Technical guidance document on risk assessment, in support of Commission Directive 93/67/EEC, Commission Regulation (EC) No. 1488/94 and Directive 9/8/EC. European Commission, European Chemicals Bureau, Institute for Health and Consumer Protection.

Esche et al., 1994 H. D. Esche, J. Traud, and H. J. Dibowski, 1994. Untersuchungen zum Vorkommen polycyclisher Moshus-Duftstoffe in verschieden umweltkompartimenten (1. mitteilung). Umweltchem, Ökotox, vol. 6, pp. 183-189.

Ferson et al., 1996 S. Ferson, L. R. Ginzburg, and R. A. Goldstein, Inferring ecological risk from toxicity bioassays, Water Air Soil Pollut., 90 (1996), pp. 71-82

Forbes et al., 2006 V. E. Forbes, A. Palmqvist, and L. Bach, The use and misuse of biomarkers in ecotoxicology, Environ. Toxicol. Chem., 25 (2006), pp. 272-280

Forbes and Calow, 1999 V. E. Forbes and P. Calow, Is the per capita rate of increase a good measure of population-level effects in ecotoxicology?, Environ. Toxicol. Chem., 18 (1999), pp. 1544-1556

Forbes and Calow, 2002 V. E. Forbes and P. Calow, Population growth rate as a basis for ecological risk assessment of toxic chemicals, Philos. Trans. R. Soc. B, 357 (2002), pp. 1299-1306

Fromme et al., 2001a H. Fromme, T. Otto, and K. Pilz, Polycyclic musk fragrances in fish samples from Berlin waterways, Germany, Food Addit. Contam., 118 (11) (2001), pp. 937-944

Fromme et al., 2001b H. Fromme, T. Otto, and K. Pilz, Polycyclic musk fragrances in different environmental compartments in Berlin (Germany), Water Res., 35 (1) (2001), pp. 121-128

Gatermann et al., 2002 R. Gatermann, S. Biselli, H. Hühnerfuss, G. G. Rimkus, M. Hecker, and L. Karbe, Synthetic musks in the environment. Part 1: Species-dependent bioaccumulation of polycyclic and nitro musk fragrances in freshwater fish and mussels, Arch. Environ. Contam. Toxicol., 42 (2002), pp. 447-453

Hall et al., 2006 R. O. Hall Jr., M. F. Dybdahl, and M. C. Vanderloop, Extremely high secondary production of introduced snails in rivers, Ecol. Appl., 16 (2006), pp. 1121-1131

Hansen et al., 1999a F. T. Hansen, V. E. Forbes, and T. L. Forbes, Effects of 4-n-nonylphenol on life-history traits and population dynamics of a polychaete, Ecol. Appl., 9 (2) (1999), pp. 482-495

Hansen et al., 1999b F. Hansen, V. E. Forbes, and T. L. Forbes, Using elasticity analysis of demographic models to link toxicant effects on individuals to the population level: An example, Funct. Ecol., 13 (1999), pp. 157-162

HERA, 2004 Human and Environmental Risk Assessment, 2004. Human and environmental risk assessment on ingredients of household cleaning products, polycyclic musks AHTN (CAS 1506-02-1) and HHCB (CAS 1222-05-05). Environmental Section, version 2. 0.

Horii et al., 2007 Y. Horii, J. L. Reiner, B. G. Loganathan, K. S. Kumar, K. Sajwan, and K. Kannan, Occurrence and fate of polycyclic musks in wastewater treatment plants in Kentucky and Georgia, USA, Chemosphere, 68 (2007), pp. 2011-2020

Jacobsen and Forbes, 1997 R. Jacobsen and V. E. Forbes, Clonal variation in life-history traits and feeding rates in the gastropod Potamopyrgus antipodarum: Performance across a salinity gradient, Funct. Ecol., 11 (1997), pp. 260-267

Jacobsen et al., 1996 R. Jacobsen, V. E. Forbes, and O. Skovgaard, Genetic population structure of the prosobranch snail Potamopyrgus antipodarum (Gray) in Denmark using PCR-RAPD fingerprints, Proc. R. Soc. London $B, 263$ (1996), pp. 1065-1070

Jensen et al., 2001 A. Jensen, V. E. Forbes, and E. D. Parker, Variation in cadmium uptake, feeding rate and life-history effects in the gastropod Potamopyrgus antipodorum: Linking toxicant effects on individuals to the population level, Environ. Toxicol. Chem., 20 (11) (2001), pp. 2503-2513

Kammenga et al., 1996 J. E. Kammenga, M. Busschers, N. M. Van Straalen, P. C. Jepson, and J. Bakker, Stress induced fitness reduction is not determined by the most sensitive life-cycle trait, Funct. Ecol., 10 (1) (1996), pp. 106-111

Kaufmann, 1981 K. W. Kaufmann, Fitting and using growth curves, Oecologia, 49 (1981), pp. 293-299
Kannan et al., 2005 K. Kannan, J. L. Reiner, S. H. Yun, E. E. Perrotta, L. Tao, B. Johnson-Restrepo, and B. D. Rodan, Polycyclic musk compounds in higher trophic level aquatic organisms and humans from the United States, Chemosphere, 61 (5) (2005), pp. 693-700

Kupper et al., 2004 T. Kupper, J. D. Berset, R. Etter-Holzer, R. Furrer, and J. Tarradellas, Concentrations and specific loads of polycyclic musks in sewage sludge originating from a monitoring network in Switzerland, Chemosphere, 54 (8) (2004), pp. 1111-1120

Lach and Steffen, 1997 G. Lach and D. Steffen, Orientierende untersuchungen von gewässersediment auf nitro-/poly- moshusverbindungen und die flammschutzmittel TCEP und TCPP, Oberirdische Gewässern grwfWasser Abwasserwes, 137 (1997), pp. 154-155

Lande, 1988 R. Lande, Demographic models of the northern spotted owl (Strix occidentalis caurina), Oecologia, 75 (1988), pp. 601-607

Levin et al., 1996 L. Levin, H. Caswell, T. Bridges, C. Dibacco, D. Cabrera, and G. Plaia, Demographic responses of estuarine polychaetes to pollutants: Life Table Response Experiments, Ecol. Appl., 6 (1996), pp. 1295-1313

Linke-Gamenick et al., 1999 I. Linke-Gamenick, V. E. Forbes, and R. M. Sibly, Density-dependent effects of a toxicant on life-history traits and population dynamics of a capitellid polychaete, Mar. Ecol. Prog. Ser., 184 (1999), pp. 139-148

Lopez and Levinton, 1987 G. R. Lopez and J. S. Levinton, Ecology of deposit-feeding animals in marine sediments, Q. Rev. Biol., 62 (1987), pp. 235-260

Moldovan, 2006 Z. Moldovan, Occurrences of pharmaceutical and personal care products as micropollutants in rivers from Romania, Chemosphere, 64 (2006), pp. 1808-1817

Nakata et al., 2007 H. Nakata, H. Sasaki, A. Takemura, M. Yoshioka, S. Tanabe, and K. Kannan, Bioaccumulation, temporal trend, and geographical distribution of synthetic musks in the marine environment, Environ. Sci. Technol., 41 (2007), pp. 2216-2222

Peck and Hornbuckle, 2004 A. M. Peck and K. C. Hornbuckle, Synthetic musk fragrances in Lake Michigan, Environ. Sci. Technol., 38 (2004), pp. $367-372$

Pfister, 1998 C. A. Pfister, Patterns of variance in stage-structured populations: Evolutionary predictions and ecological implications, Proc. Natl. Acad. Sci. USA Ecol., 95 (1998), pp. 213-218

Plassche and Balk, 1997 E. J. Plassche \& F. Balk, 1997. Environmental risk assessment of the polycyclic musks AHTN and HHCB according to the EU-TGD. Report 601503008, National Institute of Public Health and the Environment, Bilthoven, the Netherlands.

Ponder, 1988 W. F. Ponder, Potamopyrgus antipodarum-a molluscan coloniser of Europe and Australia, J. Mollus. Stud., 54 (1988), pp. 1071-1080

Reiner and Kannan, 2006 J. L. Reiner and K. Kannan, A survey of polycyclic musks in selected household commodities from the United States, Chemosphere, 62 (2006), pp. 867-873

Reiner et al., 2007 J. L. Reiner, J. D. Berset, and K. Kannan, Mass flow of polycyclic musks in two wastewater treatment plants, Arch. Environ. Contam. Toxicol., 52 (2007), pp. 451-457

Rimkus, 1999 G. Rimkus, Polycyclic musk fragrances in the aquatic environment, Toxicol. Lett., 111 (1-2) (1999), pp. 37-56

Sibly et al., 2000 M. Sibly, F. T. Hansen, and V. E. Forbes, Confidence intervals for population growth rate of organisms with two-stage life histories, Oikos, 88 (2000), pp. 335-340

Simonich et al., 2000 S. L. Simonich, W. M. Begley, G. Debaere, and W. S. Eckhoff, Trace analysis of fragrance materials in wastewater and treated wastewater, Environ. Sci. Technol., 34 (6) (2000), pp. 959-965

Simonich et al., 2002 S. L. Simonich, T. W. Federle, W. S. Eckhoff, A. Rottiers, S. Webb, D. Sabaliunas, and W. de Wolf, Removal of fragrance materials during US and European wastewater treatment, Environ. Sci. Technol., 36 (13) (2002), pp. 2839-2847

Widarto et al., 2004 T. H. Widarto, M. Holmstrup, and V. E. Forbes, The influence of nonylphenol on life-history of the earthworm Dendrobaena octaedra Savigny: linking effects from the individual- to the populationlevel, Ecotoxicol. Environ. Saf., 58 (2004), pp. 147-159 